\section{BETTER ISOLATION EQUALS BETTER DENTISTRY}

\section{乙HENRY SCHEIN ${ }^{\circledR}$ DENTAL}

Award-winning, state-of-the-art dental isolation from Isolite Systems is now available from Henry Schein Dental.

Isolite is the only dental isolation system that delivers illumination, suction and retraction in one simple, time-saving system, providing uninterrupted access and total control of the oral environment.

Isolite provides two channels of continuous hands-free vacuum suction with brilliant and adjustable LED illumination, including a 'Cure Safe' mode for light-sensitive materials. Dual vacuum control enables suction to be focused in the upper or lower quadrant, providing tongue and cheek retraction ensuring control of moisture and oral humidity at all times.

The Isovac Dental Isolation Adapter has been designed with dental hygiene procedures in mind. Isovac makes it easy to control the oral environment providing the same isolation and retraction advantages of the Isolite mouthpiece during single handed hygiene consultations.

Isolite and Isovac offer dental practitioners a range of options for minimally invasive dental isolation for every patient, whatever the procedure. For more details contact Henry Schein on Freephone 0800 0284870 or visit henryschein.co.uk.

\section{OPEN FOR BUSINESS}

QMUL is delighted to announce that the new integrated three-year DClinDent postgraduate programme (540 credits) for dentists who want to specialise in periodontology is officially launched and open for applications.

The full-time degree provides a sound basis for preparing for the membership examinations of the Royal Colleges, for a career as a specialist in the discipline of

\section{BROADEN YOUR HORIZONS}

If you are looking for ways in which to potentially grow your patient base and profits, Munroe Sutton is currently offering marketing opportunities for dental practices across the UK.

By joining the Munroe Sutton network, you will become a recommended practice to prospective patients seeking treatment. The company works with leading insurance, finance and healthcare companies to conveniently and effectively promote your services to patients signed up to insurance policies.

What's more, it guarantees immediate payment for any dental work carried out on the day the patient receives treatment.

Contact Munroe Sutton today on 08082343558 or visit www.munroesutton.co.uk.

\section{TO SELL OR NOT TO SELL?}

Now more than ever, if you are an NHS Dental Practice owner, there is one thing you can be certain of - uncertainty.

We also have seen the meteoric rise of the value of

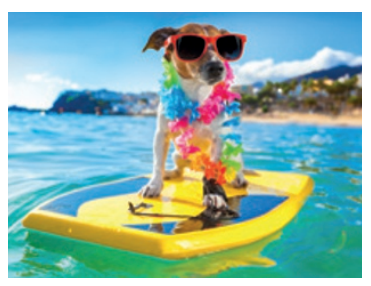
private dental practices, clearly driven by the uncertainty of NHS contracts, the increased administrative burden of NHS practice life, and the desire by investors to look at private dentistry as a growth market.

The last few years have been a whirlwind in practice values.

For example, if you are the proud owner of a NHS dental practice with a contract worth $£ 500,000$ and you bought it for $105 \%$ of the turnover in 2010, today you may be able to sell your practice for 180\% of the total turnover. Tomorrow, with the many uncertainties in the market, you may not achieve such a result.

Contact the Samera Team for a free valuation on www. sellingyourpractice.com or 08000147647.

periodontology or for developing an academic career. It integrates academic activities with clinical practice and research up to level 8 of FHEQ and covers all the topics in the GDC (UK) specialist curriculum.

The course combines strengths in clinical periodontology, implant dentistry, epidemiological and public health research in dentistry along with a solid research base in basic science in periodontology. It also brings together a range of multi-disciplinary teams with the main focus on areas including: periodontal regeneration, mucogingival surgery and implant dentistry. It is accommodated in the newly opened dental school at the new Royal London hospital, a £78 million project with the latest advanced dental technology in place.

\section{BUILDING YOUR PERIO KNOWLEDGE}

PerioAcademy is a certificate course set up and founded by two specialist periodontists, Drs Algraffee and Malaki. The goal was to provide knowledge and practical skill and experience in the field of periodontology.

PerioAcademy was designed to deliver and maximise periodontal education for the dental team in a relaxed, modern and open environment. The unique course is held in a state of the art purpose dental teaching facility in London. Courses are practical based and held once a month on a Saturday

After completion of the certificate course, colleagues will:

- Have thorough knowledge of treatment planning periodontal cases

- Have understanding of nonsurgical and surgical periodontal techniques. Be able to apply these techniques to practice

- Be able to confidently design and execute flap design for surgical techniques such as crown lengthening pocket reduction, gingivectomy, regeneration, periimplantitis and recession

- Be able to apply templates, fee structure, and ethical and profitable periodontics to your practice.

Mentoring during and after the course is provided at no extra cost. Contact info@perioacademy.co.uk or www.perioacademy.co.uk for more information.

It is taught by academics who are leaders in the field, with the latest opening of the new Clinical Oral Research Centre under the leadership of Professor N. Donos. The recruitment of Professor N. Donos is supported by the development of new, dedicated clinical research facilities within the new hospital.

For applications or further enquiries, visit www.qmul.ac.uk/dclindent-periodontology or contact the course director D. Chatzopoulou on d.chatzopoulou@qmul.ac.uk. 